\section{Brain, Behavior \\ and Evolution}

Arias, J.L. 154

Behrend, O. 97

Carr, C.E. 131

Chagnaud, B.P. 98

Christensen-Dalsgaard, J. 131

Engelmann, J. 98
Fritzsch, B. 98

Glover, J.C. 98

Grothe, B. 97

Nieuwenhuys, R. 117

Ocaña, F.M. 154

Puelles, L. 171
Rodríguez, F. 154

Salas, C. 154

Straka, H. 97, 98

ten Donkelaar, H.J. 97

Uceda, S. 154

Walton, P.L. 131

Wullimann, M.F. 97, 190

\title{
Subject Index Vol. 90, No. 2, 2017
}

Archosaurs 131

Birds 131

Brain development 171

- models 171

Claustro-insular complex 171

Crocodiles 131

Cytochrome oxidase histochemistry 154

Dentate gyrus/CA3 network 154

Efferent system 98

Evolution 98

Fish 131

Forebrain evolution 154

Fundamental morphological units 117
Genoarchitecture 117

Hair cells 98

Hearing 131

Hippocampal neural network 154

- pallium 154

Homology 117

- criteria 171

Lateral line 98

Lepidosaurs 131

Lizards 131

Natural coordinate system 117

Neuromeres 117
Pallium evolution 171

- models 171

Parahippocampal region 154

Placodes 98

Sound localization 131

Spatial memory 154

Structural plan (Bauplan, blueprint) of the central nervous system 117

Teleost fish 154

Topography 117

Topology 117

Tympanum 131

Vestibular system 98 